\title{
Francisco Sierra Caballero: por uma alternativa crítica para a comunicação educativa na América Latina
}

Roseli Fígaro

Professora associada na Escola de Comunciações e Artes, professora do Programa de Pósgraduação em Ciências da Comunicação da USP. Coordenadora do Centro de Pesquisa em Comunicação e Trabalho, CPCT. Diretora editoral da revista Comunicaşão E̊ Educação. E-mail: figaro@uol.com.br

Ana Flávia Marques

Jornalista, mestranda do Programa de Pós-Graduação em Ciências da Comunicação da USP, membro do Centro de Pesquisa em Comunicação e Trabalho (CPCT) e da coordenação do Centro de Estudos da Mídia Alternativa Barão de Itararé.

E-mail: anaflaviamarx@gmail.com

Resumo: Comunicação \& Educação entrevista Francisco Sierra Caballero, diretor geral do Ciespal - Centro Internacional de Estudos Superiores para América Latina, em Quito, Equador. Francisco Sierra Caballero é licenciado em jornalismo e doutor em Ciências da Informação, pela Universidade Complutense de Madrid. Decano da Faculdade de Comunicação da Universidade de Sevilha. Desde 2014, dirige a equipe do Ciespal e, desde 2015, preside a União Latina de Economia Política da Informação, da Comunicação e da Cultura, ULEPICC. Entre suas inúmeras obras, destacamos as coautorias e obras organizadas entre 2016 e 2017: "Capitalismo Cognitivo y Economía Social del Conocimiento. La lucha por el código"; "Golpes Mediáticos. Teoría y análisis de casos en América Latina"; "Capitalismo Financiero y Comunicación", todos de 2016; "Derecho a la comunicación. Procesos regulatorios y democracia en América Latina y Ecuador", 2017.

Palavras-chave: Francisco Sierra Caballero; Ciespal; Comunicação educativa; América Latina.
Abstract: Communication \& Education interviews Francisco Sierra Caballero, Ciespal (International Center for High Education in Latin America) CEO, in Quito, Ecuador. Francisco Sierra Caballero is graduated in Journalism and a PhD in Information Science at Complutuense University, in Madrid. Dean of the Faculty of Communication at Sevilha University. Since 2014, he is Ciespal's CEO and, since 2015, he presides the Latin Union of Political Economy of Information, Communication and Culture (ULEPICC). Among his numerous works, is important to emphasize the ones he co-wrote and organized in 2016 and 2017: "Capitalismo Cognitivo y Economía Social del Conocimiento. La lucha por el código"; "Golpes Mediáticos. Teoría y análisis de casos en América Latina"; "Capitalismo Financiero y Comunicación", in 2016; "Derecho a la comunicación. Procesos regulatorios y democracia en América Latina y Ecuador", in 2017.

Keywords: Francisco Sierra Caballero; Ciespal; Educative communication, Latin America. 
1. Foi uma Convenção Americana de Direitos Humanos, que subscreveu o Pacto de San José da Costa Rica (1969) pela democratização da informação.

2. A Nova Ordem Mundial da Informação e Comunicação (Nomic) foi um relatório formulado no âmbito de discussões entre 42 países do grupo não alinhado, sobretudo, do chamado Terceiro Mundo, que buscava soluções para as desigualdades nos fluxos de informação e conhecimento.

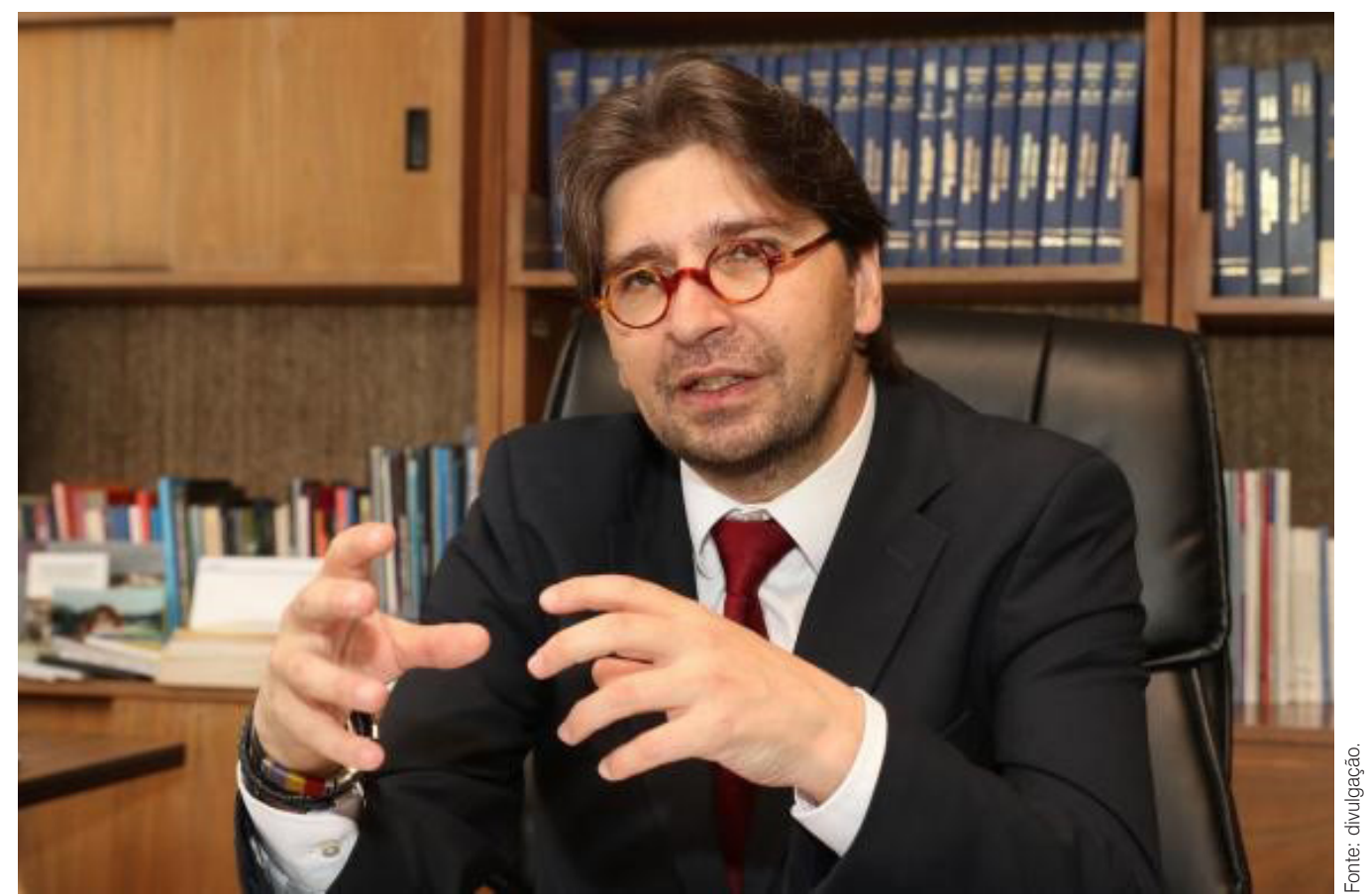

Comunicação $\mathcal{E}$ Educação: Desde sua fundação, a missão do Ciespal foi de integração regional na formação de jornalistas e comunicadores, disseminando as orientações da Unesco. E hoje, passados mais de 50 anos de sua existencia, qual e o papel do Ciespal na América Latina?

Francisco Sierra Caballero: Agradeço esse convite para a entrevista em Comunicação Ė Educação, que é uma referência na área. Esta revista propõe debates fundamentais para a pesquisa em Educomunicação, em comunicação educativa - termo que prefiro.

Bem, a história do Ciespal com a Unesco tem vários períodos. O primeiro é claramente funcionalista, o objetivo estratégico definido era capacitar: formar jornalistas e comunicadores. Somente a Faculdade Vera Cruzana, no México, e a Universidade de La Plata, na Argentina, tinham graduação para a formação de jornalistas. Então, para o Ciespal era uma prioridade a formação - um marco para a aliança para o progresso, um marco para políticas extensionista em comunidades rurais e para o desenvolvimento local —, mas com uma visão instrumental. No segundo período, começa um pensamento crítico latino-americano. Aqui em Quito, morava Ramiro Beltran que tinha articulação com Antonio Pasquali, com a Venezuela e o México, e, com o debate que começava, formula-se um pensamento desde o Sul, com uma ideia de epistemologia e de uma teoria própria. Isso tornou possível a primeira Conferência de São José de Costa Rica ${ }^{1}$, marco do debate da Nomic ${ }^{2}$, e da Revista Latinoamericana de Comunicação - Chasqui - , que se inicia muito avançada, a menos de duas décadas de vida de Ciespal, e se converte em um referente de debate sobre democracia mediática, políticas 
nacionais de comunicação, comunicação comunitária e participativa. Foi o melhor período do Ciespal. Tem continuidade na década seguinte, mas com altos e baixos. Houve projetos interessantes do Centro em parceria com a Unesco, mas o contexto político neoliberal afeta consideravelmente sua atuação. O melhor momento foi em 1979, quando o edifício sede foi inaugurado. Depois há um declínio, que chega mais ou menos até 2004 ou até 2006. E a partir daí começa o processo da revolução cidadã, no Equador - que também influencia na mudança de perspectiva da instituição em recuperar sua trajetória inicial.

Para citar um caso, o primeiro desafio que tive, ao assumir a diretoria do Ciespal, foi que o vínculo histórico entre ele e a Unesco praticamente não existia desde os anos 1990. A Unesco continuou a evoluir, mas o Ciespal não criou vias de comunicação institucionais, mas articulou-se com a OEA, resultado também do neoliberalismo, das estratégias políticas e econômicas para América Latina. Então, enfrentamos o desafio que foi retomar os vínculos com a Unesco e reforçar uma visão que chamei de governança em rede. Quer dizer, pensar a instituição como ela foi durante a década dos 1970, um Centro de conexões científicas, políticas, acadêmicas de cooperação com a Unesco, com a FAO - Organização para a Agricultura e Alimentação da ONU, com a Unicef e, praticamente, com todos os órgãos das Nações Unidas. Instituímos estreitas relações com Unasul - União das Nações Sul-Americanas, com a Celac — Comunidade de Estados Latino Americanos e Caribenhos. Temos procurado incluir no Conselho de administração as históricas entidades de comunicação que ainda não faziam parte dele, como Felafacs — Federação Latino Americana de Faculdades de Comunicação, Aler - Associação Latinoamericana de Educação Radiofônica, Alai - Agência Latino-americana de Informação, isto é, as associações regionais com vistas a reforçar a própria articulação institucional. Nós já assinamos parceria com o ILCE, que é o Instituto Latino-Americano de Comunicação Educativa, entidade da mesma época do Ciespal e, além disso, temos procurado articular com as universidades.

Nesse momento, a América Latina tem um campo científico maduro, com universidades, centros de pesquisa, programas de pós-graduação, e o papel da Ciespal não deve ser de capacitar, e, sim, articular agendas, estabelecer laços, estabelecer parcerias com as universidades - no mundo profissional, entre as autoridades públicas, sociedade civil e entre os países. Além dessas articulações, criamos o MediaLab ${ }^{3}$ para construir redes, laboratórios de TIC's na região. Também abrimos uma livraria para garantir a circulação da produção da região latino-americana, pois não se conseguem livros das diferentes unidades ou grupos de pesquisa. Ainda não alcançamos todos os objetivos, temos muito trabalho. Infelizmente, encontramos a situação desse edifício muito deteriorada e as condições das vias de comunicação institucionais debilitadas. Nosso principal papel é fazer o Ciespal ser o centro de conexões, intercâmbios, de trabalhos colaborativos das comunidades que normalmente existem nesses grupos, departamentos de universidades e
3. É um espaço de inovação, criação e experimentação de tecnologia com bases sociais, onde a experimentação e o erro são formas mais adequadas para a aprendizagem e o desenvolvimento. $\mathrm{O}$ MediaLab UIO é um nó de confluência de inovação que promove a produção social, simbólica e política de processos tecnológicos, baseados na cultura livre e em uma pedagogia inclusiva de conhecimentos acadêmicos e experiências populares, a partir de uma concepção de criação colaborativa e de comunidade. Texto extraído de: <www. medialabuio.org/node/1>. 
instituições públicas que apoiam ou pensam nacionalmente suas realidades. O Ciespal continua sendo uma organização internacional, já que a sua principal tarefa é articular redes em nível internacional. Embora com recursos limitados, estamos à procura de garantir esse trabalho em rede.

$C \mathcal{E} E$ : A produção, a circulação e o conhecimento entre os países da América Latina ainda é um desafio para todos nós. Como o Ciespal tem contribuído para essa discussão? Fale um pouco mais desse desafio...

FSC: Bem, nós temos três estratégias. Uma é, como mencionei anteriormente, a livraria. A livraria hoje não é só um espaço pensado fisicamente, ela está on-line e foi projetada para autogestão, pois gera recursos para o Ciespal que não tínhamos antes. Só para dar um exemplo, nossa produção de revistas e livros era tão deficitária que não circulavam. Se você visitava o Centro tinha que ir a um armazém, que estava fechado, alguém teria de abrir, onde não se encontravam os livros, onde não havia material. Como visitante regular da instituição me surpreendeu que os livros publicados, mais ou menos bem editados, não tinham uma distribuição. Agora a livraria tem a função de difundir essa produção. Fizemos uma plataforma de comércio eletrônico e difundimos uma produção científica de toda a América Latina, assinamos acordos e insistimos que nós queremos realizar tal feito. Porque on-line nós podemos fazer isso, isto é, hoje não há justificativa para que não ocorra a conexão do conhecimento, já que existem plataformas e ferramentas que nos permitem essa circulação.

A segunda estratégia são as cátedras — elas têm o papel de criar um corpo de ilustres colegas acadêmicos para organizar as políticas científicas que nós acreditamos como de referência para a América Latina. Mas o que é fundamental é criar comunidades epistêmicas, ou seja, além dos colegas especialistas que estão nas cátedras, estamos procurando construir redes. Recentemente, por exemplo, com a FAO, estamos criando uma rede de peritos em comunicação e desenvolvimento rural. Eu trabalhei nisso por um tempo na cátedra de Educação, Comunicação e Bem Viver. Queremos também criar redes de teorias críticas latino-americans na cátedra Jesús Martín-Barbero; conexão e trabalho colaborativo, também nessa linha de economia política, que será dedicada, por exemplo, à convergência das TICs. Estamos tentando construir redes que criem redes. Tínhamos estabelecido novos orçamentos para alimentar o trabalho destas, mas, infelizmente, hoje com a crise econômica regional, não vamos poder financiar. Apesar disso, a ideia das comunidades epistêmicas é para trabalhar essas políticas e acredito que o modelo para seguir essa política é o exemplo de Clacso - Conselho Latinoamericano de Ciências Sociais, que tem crescido exponencialmente. Portanto, as comunidades não têm que estar em contato físico, elas podem ser comunidades que trabalhem em estreita colaboração entre si, e nisso acredito que o trabalho do Ciespal é estratégico.

E a terceira meta tem a ver com a cooperação pública e multilateral. Estamos tentando gerar uma articulação através de projetos aplicados com as Nações Unidas e com a Unasul — projetos que implicam contato. O caso da 
FAO que nos encomendou um estudo sobre experiências na América Latina de Comunicação Rural Participativa e Plural é um exemplo. Nesse trabalho, articulamos uma rede com os pesquisadores não só do Ciespal, mas da Bolívia e Argentina, com o objetivo de crescer com esses projetos aplicados e de cooperação. E, de algum modo, começar a realizar trabalhos de colaboração nos projetos aplicados no território que emanam dos governos. Temos agora um lindo projeto sobre as negociações de paz na Colômbia. Vamos fazer uma plataforma de participação on-line para o diálogo e aconselhamento, que terá lugar entre o Exército de Libertação Nacional e o governo da República da Colômbia.

Mas as duas primeiras metas são fundamentais. Temos avançado um pouco com a livraria, garantindo que as universidades e grupos de pesquisa possam divulgar suas produções nela e em sua plataforma digital. Mas a segunda, para mim, é ainda mais importante: construir redes de pesquisa e cooperação. É difícil trabalhar com uma lógica de colaboração, porque os pesquisadores continuam atuando com dinâmicas de grupo, fechadas, apenas nacionais. É difícil trabalhar em rede.

No entanto, a minha experiência em trabalhar em redes é muito positiva e, por isso, temos procurado desde que eu cheguei, em junho de 2014, assinar convênios com as principais universidades do México, Colômbia, Brasil, Chile, Argentina e estamos trabalhando para tentar que encontrem redes de trabalhos através do Ciespal, de forma colaborativa. Nosso papel fundamental é que isso contribua, de alguma forma, a curto e médio prazo, para difundir e divulgar os trabalhos de pesquisa feitos pelos acadêmicos da rede.

$C \mathcal{E}{ }^{2} E$ : Para explicar o cenário atual, fale um pouco sobre como a globalização e as tecnologias digitais abrem e fecham portas para a maioria das populações. Em sua opinião, como acontece isso na América Latina em termos de acesso, liberdade de expressão e participação?

Figura 1: Livro, lançado no Ciespal em 2016: Golpes Midiáticos — Teorías y análisis de casos em América Latina, trata das inúmeras intervenções políticas realizadas na América Latina com apoio dos meios de comunicação

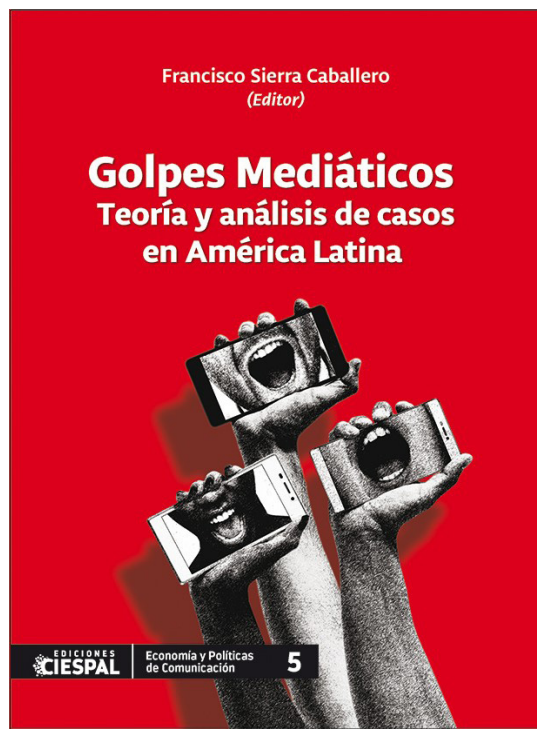


4. Movimento de estudantes mexicanos que se mobilizaram, em 2012, pela democratização da mídia e contra o candidato à presidência do PRI (Partido Revolucionario Institucional), Enrique Peña Nieto, após declarações que banalisavam a forte repressão e assassinato de jovens estudantes no estado do México.

5. Movimentos grevistas de agricultores em 2013 e 2014 na Colômbia, contra os preços abusivos dos insumos agrícolas.

6. Movimento dos estudantes secundaristas em 2006 que paralisou as escolas em todo o Chile com a participação de mais de um milhão de estudantes.
FSC: Bem, nós temos exemplos muito claros. Lançamos, em 2016, um livro entitulado Golpes Mediáticos - Teoría y análises de casos em América Latina. $\mathrm{Na}$ obra analisamos, por exemplo, no caso do Brasil, como as redes sociais foram utilizadas para o golpe. Temos também o exemplo da experiência vivida, no caso do México, na direção oposta, no movimento Yo soy $132^{4}$, cujo objetivo foi, mediante a falta de liberdade de informação imposta pela Televisa (conglomerado de mídia mexicano), garantir vozes cidadãs para apresentar alternativas democráticas de governo. Então, como acontece em qualquer processo, as TICs têm, por um lado, um sistema de domínio e controle; e, por outro, um processo inverso. Temos falado muito sobre isso e criamos a cátedra Julian Assange para discutir Tecnopolítica. Tal área tem ajudado a compreender esse processo contraditório: como as redes sociais estão sendo usadas para o golpismo. E aí analisamos o caso do Equador, de uma tentativa de golpe no ano passado, juntamente com o caso do Brasil - e como com a ajuda das TIC's, surgem outros processos no sentido inverso - como se deu a paralisação no campo, denominado paro agrário ${ }^{5}$, na Colômbia, o movimento Yo soy 132, no México, e a Revolução dos Pinguinss, no Chile. Falo isso porque normalmente há um mito sobre as TICs na globalização. O mito de que ela é uma estrutura descentralizada, autônoma e que pode garantir acesso e, portanto, a democracia. E esse mito é falso, já que existe um dispositivo de controle e isso tem sido demonstrado, por exemplo, nas mobilizações no Brasil, na forma que as redes deixam de funcionar, como elas podem realizar intervenções, ou como ajudam a organizar um golpe de Estado através de redes sociais, como o Movimento Brasil Livre. Logicamente com a intervenção financeira dos Estados Unidos, da agência CIA de cooperação. É evidente que tem uma função instrumental, de controle e vigilância, como fala Armand Mattelart - insisto muito nessa ideia, porque isso tem a ver com a criminologia, tem a ver com a biopolítica que é criticada por Michel Foucault. Os sistemas de criar perfis e de construir o inimigo em potencial, ou o que se chamava de Psicologia da Multidão, as massas perigosas, multidões perigosas. Nessa acepção, a priori todos os indivíduos da rede são perigosos até que se prove o contrário. Isto é um dispositivo. Também devemos lembrar que o Sistema Internacional de Telecomunicações está ultraprivatizado pelo UIT, um órgão antidemocrático, que regula a rede de internet, sob o domínio da Agência de Segurança Nacional — NSA, com hegemonia absoluta dos Estados Unidos, para interferir, vigiar e organizar golpes de Estados nos países do Sul.

Em decorrência disso, essas políticas colonizaram as políticas de meios analógicos e das estruturas de telecomunicações. E, por exemplo, temos a mercantilização que está permeando as políticas de comunicação pública. Estou falando isso porque não é um assunto que normalmente é discutido, mas temos o caso, no Equador, que quando fica vigente a radiodifusão comunitária, quem aplica o processo de concessão é um organismo que age com uma filosofia de telecomunicações da UIT. E, como já disse, a UIT, desde seu início, constrói 
um sistema internacional de telecomunicações sob a hegemonia absoluta dos Estados Unidos.

E, por outro lado, acredito que existe uma demanda central por pesquisas sobre as TICs, sendo tais uma agenda pendente. Essa é uma questão que se deve trabalhar na pesquisa acadêmica latino-americana, não só porque tem uma centralidade nos processos de mudança, de modos de produção, padrões de consumo, de processos de criatividade, mas, além disso, porque estão acontecendo nas novas gerações surtos criativos, potencialidades emancipatórias que temos de analisar. Por isso, criamos na CLACSO um grupo de trabalho, o GT denominado de Tecnopolítica, Cidadania Digital e Processos de Mudança e tentamos conectar a dimensão cidadã, criativa e transformadora aos processos de ação e mobilização coletiva em todos os sentidos, a exemplo dos movimentos de $Y_{o}$ soy 132, no México, o paro agrário na Colômbia, e outros como Mídia Ninja do Brasil. Políticas públicas para discutir o que é governo, o que é a democracia, por que ela é importante e como ela é possível a partir de políticas de Estado.

Figura 2: Lançamento 2017 das edições Ciespal, Derecho a la comunicacion. Procesos regulatórios y democracia en America Latina

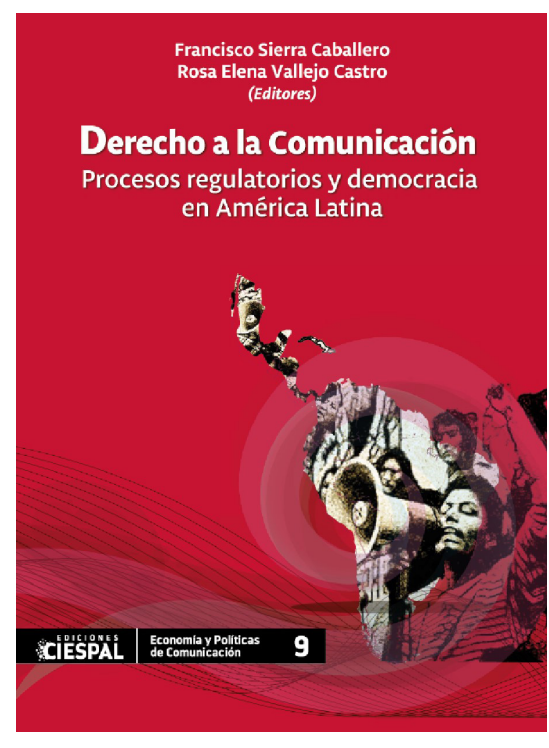

Não falei ainda de um outro mito, que defende a ideia de que as tecnologias não são ajustáveis, de que a internet não pode ser regulada. Sim, ela é regulável e deve ser regulada. O Marco Civil da Internet no Brasil, assinado, em 2014, pela presidente Dilma Rousseff, é um exemplo que isso pode ocorrer. E, além disso, garante a democracia contra certo discurso alternativo, autônomo, sobre o que chamo criticamente, de "anarcopop", que pensa que qualquer lei é uma armadilha para impedir a liberdade de expressão. De jeito nenhum. De um lado, analisamos o que se passa na Bolívia, o que foi vivido no Equador, e como as políticas da UIT e os interesses hegemônicos dos Estados Unidos podem desestabilizar os governos, fazer guerras, ou possíveis guerras. De outro lado, permitem também alternativas de mobilização e autoconvocações de jovens e 
7. Trata-se de Karl Marx (1818-1883), pensador alemão que estudou o capitalismo como sistema de propriedade privada baseado na acumulação de riquezas e na exploração do trabalho da maioria da população. Sua obra maior é O Capital. Sua compreensão do capitalismo, a partir do método do materialismo dialético, fez com que visse a História como a ciência que nos permite entender a realidade para transformá-la. movimentos sociais. Nesse sentido, é preciso ter atenção. Temos, justamente no livro sobre o Golpe Midiático, muitos capítulos dedicados à gestão da rede, por exemplo, e todas as contradições da globalização que permitem o uso repressivo da biopolítica contemporânea, mas também, a mobilização e a resistência. Por isso, devemos ser críticos com o mito das TICs como democracia; e outro que se vincula ao discurso da globalização das TICs como empreendedorismo e criatividade. O Panama Papers é um exemplo, propõe-se como jornalismo colaborativo entre diferentes países, mas quem financia esse jornalismo? Por que ali não aparecem as principais fortunas dos Estados Unidos e os "lobos de Wall Street"? Isso é fazer jornalismo inovador, simplesmente porque colaboram através da internet, filtrando algumas fontes de poder interessadas? Aí não há uma mudança significativa. Há a repetição do mito de que com as TICs, desde o surgimento da radiodifusão, iríamos alcançar a democracia, a paz, a compreensão intercultural, o diálogo entre os povos do planeta e o irmanamento - e não é bem assim. As TICs são dispositivos de controle, mas também permitem alguns processos emancipatórios interessantes.

$C \mathcal{E} E$ : Então, você pode nos falar um pouco mais deste livro Golpe Midiático?

FSC: Nós provavelmente apresentaremos este livro em Brasília, em parceria com a UnB, e terei todo o prazer em apresentar também na USP, já que analisa um pouco a perspectiva regional de São Paulo. Outro livro que estamos preparando, e trabalhei bastante nele por circunstâncias da vida, é sobre o tema das guerras e da propaganda. É um livro sobre as guerras imperialistas na América Latina a partir dos meios de comunicação. A Guerra da Informação faz análises a partir da aliança para o progresso, da Segunda Guerra Mundial até os nossos dias. Falamos sobre as estratégias dos EUA, ou seja, sua intervenção na América Latina, dedicando algumas referências à Venezuela, Brasil, Equador, México e apresentando alguns casos e exemplos.

$C \mathcal{E} E^{2}$ : Então, a internet e as redes sociais não são essas maravilhas revolucionárias que trazem por si só democracia participativa. Como podemos entender que muitos intelectuais ainda representam essa ideia? $\mathrm{E}$ como enfrentar esses pensamentos? $O$ que podemos fazer?

FSC: Bem, existem várias coisas que se tem de fazer. Primeiro, é refletir sobre o papel da tecnologia. As tecnologias não são neutras, elas têm códigos culturais, são portadoras de ideologias. Então, não podemos pensar os meios com essa leitura centrada na mídia, que os meios são canais, instrumentos, não! Eles são dispositivos culturais. Se não fizermos esta leitura, deixaremos de politizar as TICs. Ou seja, como inovam? Onde é que elas produzem? Como é transferida? Em que contexto é implementada? Como a implantação das tecnologias pressupõe uma transformação organizativa?

É evidente, após Marx ${ }^{7}$, sabemos que toda a transformação tecnológica, toda inovação afeta as condições de trabalho, ou seja, existe uma precariedade, uma proletarização da força de trabalho. Não se importam tecnologias apenas 
assumindo o discurso de empreendedorismo, de inovação. A inovação tem várias leituras. Tem uma leitura marxista de economia política crítica e tem uma leitura shumpeteriana ${ }^{8}$ que entende a inovação em si mesmo e por aí vai. Primeiro, temos de desmistificar a ideia de tecnologia como dispositivo neutro e pensar neste processo em termos culturais. Segundo, se pensamos que é um dispositivo cultural, devemos discutir política de comunicação. Não é pertinente adaptar ou importar modelos. Isso acontece em alguns países, como o México, que inovaram nas escolas quando nem sequer os professores tinham um salário digno. Todos, no governo de Vicente Fox, ganharam aulas digitais, mas a situação do ensino e aprendizagem era muito precária, tão precária que grande parte do território mais pobre do México - Guerrero, Oaxaca, Vera Cruz - não tinha professores em muitas de suas áreas rurais, já que o antigo sistema de teleducação, ensino a distância, também não foi cuidado. Então, eles tinham centros educativos com tecnologia de ponta e força de trabalho docente precária, e territórios descobertos pela oferta de educação. Politizar as TICs significa pensar nos "quês", "comos", "para quê", "onde", e "quem são os que se beneficiam?". Provavelmente o governo Fox beneficou as empresas e companhias de tecnologia dos Estados Unidos, e não atendeu a seus professores.

E a terceira dimensão, que é a mais problemática, é que nós, como acadêmicos, intelectuais, devemos repensar os modos de produção de conhecimento. Isto é, repensar e refletir como trabalhamos a pesquisa. E não vale apenas ser cientista social, que trabalha em casa com a sua biblioteca, com seu "livrinho e trabalhar escrevendo sozinho, deve-se trabalhar em rede de forma colaborativa. Quando eu falo de redes de forma colaborativa, isso envolve também a produção de conhecimento de trabalho com as TICs, com a cidadania, com grupos sociais, com organizações e movimentos, com pessoas que não são acadêmicos, mas têm cursos, são prossumidores ${ }^{9}$, produzem e têm espertise sobre tecnologia. Porque, pela primeira vez, na universidade, há jovens que ensinam as pessoas mais velhas, estudantes que explicam aos professores como são as tecnologias e como eles têm de se desenvolver. Inverte-se o papel do professor tradicional. Na minha época, era mais ou menos ao contrário, o professor lhe ensinava como se faz, como funcionava um teletipo, como se trabalhava... Agora você tem de aprender com o estudante o novo aplicativo, como ele é usado.

Trabalhar na lógica do diálogo é saber de lógica colaborativa, implica um modo de produção de conhecimento que deve ser consubstancial e, portanto, não apenas um objeto de estudo, mas também um ambiente de como podemos trabalhar a pesquisa. Isso nos obriga, por exemplo, a nós, pessoas de comunicação, de comunicologia - que definimos a nossa ciência como uma ciência aplicada - a trabalhar com outras linguagens, não apenas a leitura e a escrita, mas também com imagens, com a visualização de dados, trabalhar com o big data, com uma elaboração, posso dizer, ampliada. Isto é difícil para nós, acadêmicos de comunicação, porque as TICs estão
8. Joseph Alois Schumpeter (1883-1950) foi economista austro-húngaro. Seus estudos sobre o capitalismo tratam de conceitos como inovação, empreendedorismo, destruição criativa; para ele o capitalismo deve ser estudado a partir de crescimento e desenvolvimento para o aumento da produtividade.

9. São produtores e consumidores e se beneficiam do trabalho coletivo. 
em nossa área, é um objeto e nos transforma de forma radical e acelerada com as formas de trabalho na rede, no processo da cultura ou da galáxia internet. Nessa junção, o desafio é difícil, é em dose dupla. Trabalhar com objetos que envolvem a pesquisa e a comunicologia com modelos de redes e tecnologias e, além disso, trabalhar com outros métodos e formas de ensino, aprendizagem e pesquisa. E isso é complicado. O grande desafio - uma tradição latino-americana, que ocorreu na década dos 1970 e dos 1990 e tende a se recuperar - é a questão da extensão, a questão da ligação com a mídia social, os papéis sociais que essas outras universidades, a europeia, luso-hispanica e latino-americana têm agora nessa complexa realidade hipermediatizada tecnologicamente. Senão vamos ser personagens de Rice Burroughs ${ }^{10}$, perdidos na fatalidade da tecnologia em uma distopia absoluta, que inclusive contesta o papel da universidade, da academia.

\section{$C \mathcal{E} E$ : Nessa perspectiva, como você vê a comunicação no domínio do ensino ou a educomunicação?}

FSC: Eu prefiro falar de comunicação educativa, mas é uma discussão quase nominalista. Não vamos entrar nesse assunto.

Sim, é importante.... Num livro que fez parte da minha tese de doutorado, levantei que o objeto da comunicação educativa é pensar as representações e trabalhar com discursos em termos praxiológicos. Isto é, toda representação, seja um livro de textos, seja um filme, seja uma fotografia, deve ser objeto de análise e interpretação por qualquer leitor, por qualquer usuário. E isso significa problematizar a relação entre discurso, representação, ideologia e práxis social e ir além da visão da media literacy anglo-americana, que é aprender códigos, linguagens e ferramentas. Temos de recuperar o legado de autores, dos quais nos sentimos orgulhos de identificar uma cultura, como no legado freireano, de pensar a educação como processo para alguém que escreve a história, ou seja, a partir de discursos e de representações materiais se constroem processos sociais materiais. E, na tradição da educação popular, isso significa, na era da internet, problematizar, da mesma forma, as TICs. Todavia, observamos um retrocesso com projetos de universidades virtuais, educação a distância que pretendem restaurar o modelo condutivista e centrado na mídia - esses são conceitos restritivos. E por isso, temos alguns problemas. A partir da teoria da comunicação, percebo o conceito de competência como um problema. Seus adeptos defendem desenvolver habilidades para a cultura digital. Ou seja, o conceito de competência na teoria da comunicação tem uma visão instrumental, mesmo que Noam Chomsky seja um grande intelectual crítico, sua perspectiva linguística é uma visão instrumental da aprendizagem da linguagem para o deriva da concorrência, mas é uma visão muito funcionalista. E isso é transportado aos nossos debates sobre a comunicação educativa, que têm acontecido na Unesco. Há colegas ali que usam essa lógica, muitos dos meus colegas na Espanha também. Inclusive os congressos são denominados de competência da 
cultura digital, e eu não concordo com esse modelo, porque seria limitador da comunicação. Este é um problema que deve ser discutido para pensar as representações e trazer a perspectiva da comunicação, como a compreendeu Mario Kaplún, como a compreendeu Paulo Freire, como a entendeu a tradição crítica latino-americana: que é aprender a fazer história com palavras ou aprender a fazer as coisas por representações. E as ideias de Michael Mann"11, com as que mais me identifico, aparecem quando ele fala de ensino audiovisual, no Instituto Britânico de filmografia, na Inglaterra, e são precisamente sobre identificar o paradigma crítico como o herdeiro das matrizes da teoria da ideologia marxiana, criticando como essas representações são frutos materiais concretos.

Observação importante também faz a semiótica, de que qualquer símbolo, de qualquer representação discursiva ter um grau de opacidade. Como explicava Eliseu Veron, temos de desvendar como esses discursos são construídos. São dispositivos ideológicos. Tal semióse age em nossa ideologia, em nosso imaginário e, portanto, em nosso comportamento social. Isso implica, também, que essas contradições da economia política repercutem na comunicação educativa sobre o poder, sobre o controle e o acesso na democracia contemporânea. Especialmente em tempos hipermidiáticos. Estou fascinado, ultimamente, pela literatura que nos coloca a distopia sobre o futuro do universo tecnológico e sobre a incapacidade que se tem de distinguir, numa perspectiva sociopática, entre o que são redes sociais, representações e realidades materiais. E, certamente, esse é um debate pertinente para o processo de comunicação educativa. O debate para formar um currículo, na União Europeia, tem sido muito interessante, ou seja, devemos reconhecer trabalhos intelectuais e acadêmicos de colegas para obter essa agenda como parte da política de governos. Mas, talvez por causa da falta de legitimidade social, acredita-se que a comunicação é um aspecto comercial e privativo de proprietários. Como se ela não tivesse a ver com direitos, com a educação, com a cultura, com a subjetividade. Portanto, essa situação atual condena a comunicação educativa a uma leitura que considero muito instrumental e muito pobre. Ou seja, despolitiza o recenseamento da comunicação educativa sobre a construção de representações em matéria de informação, sobre conhecimento, sobre processos de mediação.

$C \mathcal{E}$ E: Nesse sentido, como é possível ajustar os atuais projetos de educação formal às demandas do século XXI?

IA: Este é justamente nosso desafio atual: saber utilizar as tecnologias nos processos de ensino e aprendizagem, para que nos seja possível formar pessoas críticas e judiciosas, com capacidade de pensar e aproveitar. A educação, como dizia Paulo Freire, é a arma da transformação social mais importante que temos à nossa disposição, temos de saber utilizá-la para melhorar nosso futuro e o dos demais. A Educomunicação, com suas metodologias, com seus processos e aspirações, é o melhor instrumento para alcançar tal objetivo.
11. Cineasta norte-americano, roteirista e diretor de uma extensa obra cinematográfica. Entre seus filmes estão Hacker (2015), Inimigos Públicos (2009), Miami Vice (2005), Colateral (2004). 